\title{
Experimental and Theoretical Analysis of Cracking Moment of Concrete Beams Reinforced with Hybrid Fiber Reinforced Polymer and Steel Rebars
}

\author{
Hiep Dang $\mathrm{Vu}^{1}$, Duy Nguyen Phan ${ }^{2, *}$ \\ ${ }^{1}$ Civil Engineering Faculty, Hanoi Architectural University, Vietnam \\ ${ }^{2}$ Faculty of Civil Engineering, Mientrung University of Civil Engineering, Vietnam \\ Received 18 March 2021; received in revised form 11 May 2021; accepted 12 May 2021 \\ DOI: https://doi.org/10.46604/aiti.2021.7330
}

\begin{abstract}
This study aims at experimentally and theoretically investigating the cracking moment $\left(M_{c r c}\right)$ of hybrid Fiber Reinforced Polymer (FRP)/steel Reinforced Concrete (RC) beams. Six hybrid Glass FRP (GFRP)/steel and three GFRP RC beams with various GFRP and steel reinforcement ratios are tested in four-point bending scheme. Experimental results indicate that both GFRP and steel rebars affect $M_{c r c}$, but the effect of steel reinforcement is more significant. When the steel reinforcement ratio increases to $1.17 \%, M_{\text {crc }}$ goes up to $15.9 \%$, while the same value for GFRP is only 9.7\%. An analytical method is proposed based on the plain section assumption and nonlinear behavior of materials for estimating $M_{c r c}$. The proposed model shows a good agreement with the experimental data conducted in this study and collected from the literature. The results of the parametric study give evidence of the positive effects of hybrid reinforcement ratios and elastic modulus of FRP on $M_{c r c}$ of hybrid RC beams.
\end{abstract}

Keywords: concrete beam, fiber reinforced polymer (FRP), hybrid reinforcement, cracking moment, flexural behavior

\section{Introduction}

Due to some special characteristics, such as superior corrosion resistance, low strength/weight ratio, non-conductive, non-magnetic, Fiber Reinforced Polymer (FRP) rebars, are widely used as an alternative to steel rebar for concrete structures [1-2]. It is well known that there are four common types of FRP rebars used to reinforce concrete components: Aramid FRP (AFRP), Basalt FRP (BFRP), Carbon FRP (CFRP), and Glass FRP (GFRP).

Only the elastic modulus of CFRP is equivalent or higher than that of steel bar. The elastic modulus of other FRP types is much lower than that of steel bar, which causes large deflection and crack width of FRP Reinforced Concrete (RC) bending elements [3-6]. To overcome this drawback of FRP RC beams, many researchers proposed combining traditional steel bars to FRP bars in the tension zone of the concrete beam. As a result, hybrid FRP/steel RC beams are formed [7-9]. In practice, the hybrid FRP/steel RC beams were also met in a type of RC beams strengthened with FRP sheets. Although the flexural behavior of FRP/steel RC beams has been extensively investigated, the data on cracking behavior is still limited.

This study presents experimentally and theoretically the investigation on the cracking behavior of hybrid FRP/steel RC beams, and introduces an analytical method for predicting the cracking moment of FRP/steel RC beams. First, three groups of beams, which contain six hybrid GFRP/steel and three GFRP RC beams, are cast and tested in the four-point pending scheme to clarify the cracking behavior. Second, an analytical method based on the plane section assumption and strain compatibility is

* Corresponding author. E-mail address: nguyenphanduy@ muce.edu.vn Tel.: +84-917688903 
proposed for estimating the cracking moment. This method considers the nonlinear behavior of concrete and the contribution of reinforcements. Finally, a parametric study on the effect of longitudinal reinforcement ratios and elastic modulus of FRP on the cracking moment is done by using the proposed analytical method.

\section{Literature Review}

Previous studies of FRP/steel RC beams mainly focused on the flexural behavior, evaluating the cracking moment, failure modes and load-bearing capacity, short-term and long-term deflections, crack width, crack spacing, stiffness, and ductility. The results of the previous studies revealed the positive effect of steel reinforcement in improving the flexural behavior of FRP/steel RC beams [4-16]. For the design purposes of hybrid FRP/steel RC beams, many researchers proposed analytical methods to estimate load-carrying capacity [10, 12-13, 17-19] and limits of reinforcement ratios [20], to determine failure modes [10-16], and to estimate crack width, crack spacing, and midspan deflection [21-22]. Some researchers tried to use the existing design codes with some modifications for the calculation of hybrid FRP/steel RC beams [4, 18, 23-24].

Regarding the cracking moment of FRP/steel RC beams, very few researchers focused on the cracking behavior and proposed the formulas to calculate the cracking moment of FRP/steel RC beams. By using the existing design codes with the modulus of rupture and transformed uncracked sections, Mohamed [25] compared the theoretical and experimental cracking moments of FRP/steel RC beams, and reported that the theoretical cracking loads were significantly smaller than the experimental values. Kartal and Kalkan [26] developed two cracking moment estimates of FRP/steel RC beams, one for the gross moment of inertia and the other for the uncracked transformed moment of inertia. In each method, three different tensile strengths of concrete, i.e., the experimental value calculated from the prismatic beam tests and the second and third values obtained from empirical flexural tensile strength of Eurocode 2 and ACI 318M, were applied. The results showed that the uncracked transformed moment of inertia method with a modulus of rupture expression according to the ACI $318 \mathrm{M}$ gave the best agreement between theoretical and experimental results. Besides, the authors reported that ignoring the contribution of the longitudinal reinforcements in the calculation may lead to underestimation of the cracking moment.

Maleki and Kheyroddin [18] used the recommendations of ACI440.1R-15 and CSA-S806-12 to estimate the first cracking moment of GFRP/steel RC beams. The results showed that these design codes underestimated the cracking moment of tested beams. Valivonis and Skuturna [27] experimentally investigated the cracking moment of RC beams strengthened by CFRP laminates. They reported that CFRP laminates significantly increased the critical tension strains of the concrete and cracking moment (from 56\% to 106\%), and that CFRP laminates also influence the expansion of cracks and restrict the development of the crack. These authors proposed an analytical equation for estimating the cracking moment by using curvilinear diagrams to describe the compressed concrete and the concrete in tension. However, the comparison results showed a large deviation between theoretical and experimental values.

Gao et al. [28] carried out an experimental study on the flexural behavior of one-way slab strengthened by FRP sheets, and pointed out the influence of the amount of strengthening CFRP and GFRP sheets on cracking moment of RC one-way slab. In particular, the CFRP sheet with a high elastic modulus has a stronger effect on the cracking moment in comparison with a GFRP sheet. Due to the complication of a method for estimating the cracking moment based on the plane cross-section assumption and equilibrium condition, these authors proposed an equivalent-conversion method for determining the cracking moment of RC slabs strengthened with FRP, in which the formula of elastic materials is used with a plasticity coefficient. The proposed method revealed good agreement between experimental and theoretical values.

A lot of experimental research on the flexural behavior of hybrid FRP/steel RC beams has been reported along with many proposals for prediction models of cracking moments. However, the majority of these proposals are based on the existing design codes (ACI and Eurocode), which neglected the contribution of reinforcements. This fact led to the underestimation of the cracking moment of FRP/steel RC beams. 


\section{Experimental Investigation}

Six hybrid GFRP/steel RC and three GFRP RC beams with dimensions of $150 \times 250 \times 2700 \mathrm{~mm}($ width $\times$ height $\times$ long) and different GFRP and steel reinforcement ratios are cast and loaded in a four-point bending scheme. All nine testing beams are divided into three groups to evaluate the influence of GFRP/steel reinforcement on the cracking load. In each group, the GFRP reinforcement area $\left(A_{f}\right)$ is fixed, and the steel reinforcement area $\left(A_{s}\right)$ varies (Fig. 1 and Table 1). Specifically, the group of beams \#1 (beams B1, B2, and B3) is reinforced with 2G10 (two GFRP bars with a diameter of $10 \mathrm{~mm}, A_{f}=1.225 \mathrm{~cm}^{2}$ ), the group of beams \#2 (beams B4, B5, and B6) is reinforced with $2 \mathrm{G} 14\left(A_{f}=2.65 \mathrm{~cm}^{2}\right)$, and the group of beams \#3 (beams B7, B8, and B9) is reinforced with $3 \mathrm{G} 14\left(A_{f}=3.97 \mathrm{~cm}^{2}\right)$.

In addition, during the analysis of the test results, the groups of beams with fixed longitudinal steel reinforcement and varied GFRP reinforcement are also created. The group of beams with fixed 2S10 (two steel bars with the diameter of $10 \mathrm{~mm}$ ) contains beams B2, B5 and B8, and the group of beams with fixed 2S14 (two steel bars with the diameter of 14 mm) contains beams B3, B6, and B9. The loading span is $2400 \mathrm{~mm}$, of which the length of the pure bending zone is $400 \mathrm{~mm}$ (Fig. 2(a)). As shown in Fig. 1, the GFRP and steel rebars are arranged in two layers, wherein the GFRP rebars are placed in the undermost layer with a concrete cover thickness $\left(C_{f}\right)$ of $25 \mathrm{~mm}$, while the steel rebars are arranged in the inner layer (second layer) with a concrete cover thickness $\left(C_{s}\right)$ of $50 \mathrm{~mm}$. All the actual dimensions of the testing beams are re-measured after casting, as shown in Table 1. The shear reinforcements from plain round steel bars with the diameter of $6 \mathrm{~mm}$ and the spacing of $100 \mathrm{~mm}$ are put in the shear spans to prevent shear failure. In the middle span, the spacing of stirrups is $200 \mathrm{~mm}$ to form a reinforcement cage and reduce the influence of stirrups on flexural behavior. Two $6 \mathrm{~mm}$ diameter steel rebars are used as compressive reinforcements. The beam specimens are designed with references to ACI 440.1R-15 [29] and recommendations by previous researchers $[12,20]$. Accordingly, the GFRP reinforcement ratio $\left(\mu_{f}\right)$ varies from $0.35 \%$ to $1.18 \%$, and the steel reinforcement ratio $\left(\mu_{s}\right)$ ranges from $0.52 \%$ to $1.13 \%$. Details of geometries and reinforcements of specimens are presented in Table 1 .

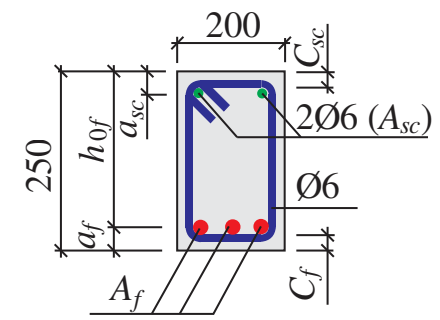

(a) GFRP RC beams

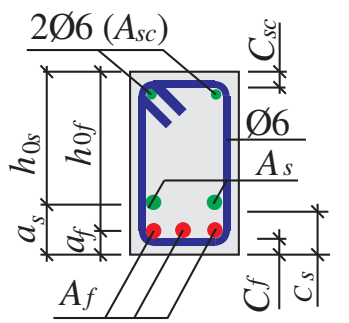

(b) Hybrid GFRP/steel RC beams

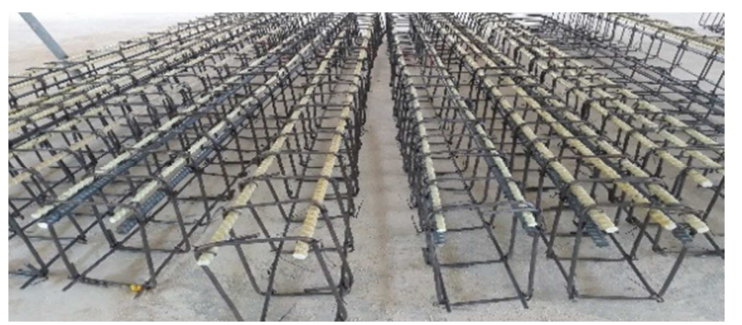

(c) Reinforcement cage

Fig. 1 Beam's reinforcement (unit: $\mathrm{mm}$ )

Table 1 Details of beam specimens

\begin{tabular}{|c|c|c|c|c|c|c|c|c|c|c|c|c|}
\hline Group of beams & Beam ID & $b, \mathrm{~mm}$ & $h, \mathrm{~mm}$ & $a_{f}, \mathrm{~mm}$ & $a_{s}, \mathrm{~mm}$ & $h_{O f}, \mathrm{~mm}$ & $h_{0 s}, \mathrm{~mm}$ & $A_{f}, \mathrm{~cm}^{2}$ & $A_{s}, \mathrm{~cm}^{2}$ & $\mu_{f}, \%$ & $\mu_{s}, \%$ & $R_{m}, \mathrm{MPa}$ \\
\hline \multirow{3}{*}{ \#1 } & B1.2G10 & 150 & 253 & 21 & - & 232 & - & 1.23 & - & 0.35 & - & 37.2 \\
\hline & $\mathrm{B} 2.2 \mathrm{G} 10-2 \mathrm{~S} 10$ & 152 & 254 & 30 & 54 & 224 & 200 & 1.23 & 1.57 & 0.36 & 0.52 & 41.6 \\
\hline & B3.2G10-2S14 & 151 & 252 & 27 & 72 & 225 & 180 & 1.23 & 3.08 & 0.36 & 1.13 & 39.5 \\
\hline \multirow{3}{*}{ \#2 } & B4.2G14 & 148 & 252 & 31 & - & 221 & - & 2.65 & - & 0.81 & - & 42.6 \\
\hline & B5.2G14-2S10 & 151 & 251 & 31 & 52 & 220 & 199 & 2.65 & 1.57 & 0.80 & 0.52 & 41.0 \\
\hline & B6.2G14-2S14 & 152 & 254 & 33 & 62 & 221 & 192 & 2.65 & 3.08 & 0.79 & 1.06 & 40.5 \\
\hline \multirow{3}{*}{ \#3 } & B7.3G14 & 148 & 255 & 26 & - & 229 & - & 3.97 & - & 1.17 & - & 45.5 \\
\hline & B8.3G14-2S10 & 153 & 254 & 33 & 59 & 221 & 195 & 3.97 & 1.57 & 1.18 & 0.53 & 42.8 \\
\hline & B9.3G14-2S14 & 155 & 255 & 23 & 58 & 232 & 197 & 3.97 & 3.08 & 1.11 & 1.01 & 42.9 \\
\hline
\end{tabular}

*Note: $b, h, a_{f}, a_{s}, h_{0 f}$ and $h_{0 s}$ are the geometric dimensions of cross section as shown in Fig. 1. $\mu_{s}=A_{s} /\left(b h_{0 s}\right)$ and $\mu_{f}=A_{f}$ $/\left(b h_{0 f}\right)$ are the steel and GFRP reinforcement ratios, respectively. The beam ID is formed from 3 parts: the first part (e.g., B1) is the order number of the beams, the second part $(2 G 10,2 G 14$, and 3G14) refers to the number and the diameter of GFRP bars, and the last part (2S10 and 2S14) indicates the number and the diameter of steel bars. B refers to beam, G refers to $G F R P$, and $S$ refers to steel. 


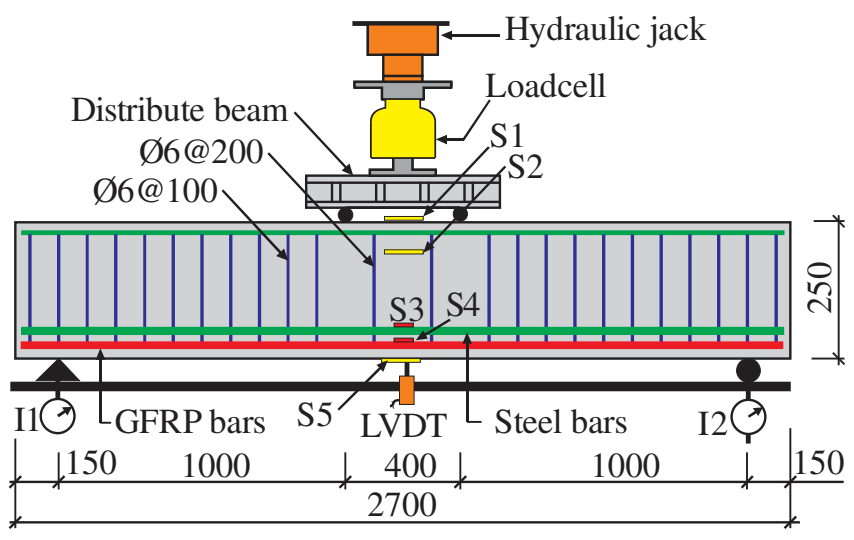

(a) Schematic diagram

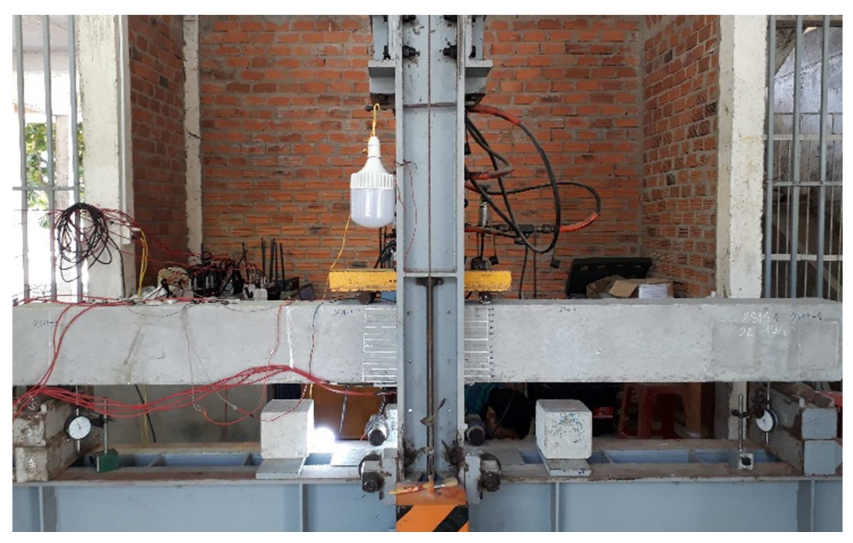

(b) Test setup

Fig. 2 Flexural test

The concrete with the desired compressive strength of $40 \mathrm{MPa}$ and the water-to-cement ratio of 0.55 is produced from ordinary Portland cement. The actual average compressive strength $\left(R_{m}\right)$ is evaluated from compressive tests on $150 \times 150 \times$ $150 \mathrm{~mm}$ cubic specimens after 28 days of curing, as shown in Table 2. The ribbed GFRP rebars with nominal diameters of 10 $\mathrm{mm}$ and $14 \mathrm{~mm}$ are used in this study and are manufactured by Vietnam FRP Trading and Production Joint Stock Company. The GFRP bars are produced from continuous high-strength E-glass fiber and vinyl ester resin. The hot-rolled plain steel bar with a diameter of $6 \mathrm{~mm}$ is used for stirrups and compressive reinforcement, and the hot-rolled ribbed steel bars with diameters of $10 \mathrm{~mm}$ and $14 \mathrm{~mm}$ are used as longitudinal rebars. The mechanical properties of GFRP, round plain steel, and ribbed rebars according to tensile tests are shown in Table 2.

Table 2 Mechanical properties of reinforcements

\begin{tabular}{|c|c|c|c|}
\hline Rebars & Yield strength, MPa & Tensile strength, MPa & Young's modulus, GPa \\
\hline GFRP & - & $R_{f}=997$ & $E_{f}=44.3$ \\
\hline The 6 mm plain round steel & $\sigma_{s y}=309$ & $R_{s}=358$ & $E_{s}=200$ \\
\hline The ribbed steel (diameter $\geq 10 \mathrm{~mm}$ ) & $\sigma_{s y}=412$ & $R_{s}=577$ & $E_{s}=200$ \\
\hline
\end{tabular}

The beams are loaded after a 28-day curing period in a four-point bending scheme until failure (Fig. 2). Three $100 \mathrm{~mm}$ strain gauges (S1, S2, and S5) are placed at the top, side, and bottom surfaces at the midspan of the test beams to record the compressive and tensile strains in concrete. Two $5 \mathrm{~mm}$ strain gauges (S3 and S4) are attached on the surface of tensile steel and GFRP rebars at midspan before casting and are protected by silicon to measure the strains in rebars during the test. A Linear Variable Differential Transformer (LVDT) is fixed at midspan to measure the deflection, and two digital indicators I1 and I2 are placed at supports to eliminate the displacements of holders. During the test, the loads on the beam are applied in a step-by-step procedure, and the values of load from loadcell, the data from LVDT, and strain gauges are automatically collected by the datalogger STS-WIFI system.

\section{Experimental Results and Discussion}

The first cracking moment of tested beams is obtained from the load versus strain curve of the concrete and reinforcements. This value can also be determined from the load versus midspan deflection curve. Fig. 3 and Fig. 4 illustrate the load-strain and load-midspan deflection curves for a typical tested beam B2.2G10-2S10. It is worth to note that until the yield of steel (after the concrete cracks), the trends of the load versus strain curves of the concrete and reinforcements and the load versus midspan deflection curves of the remained tested beams are similar to those of the beam B2.2G10-2S10. As shown in Fig. 3, there are leaps on the load-strain curves as the first crack appears. The leap is also noticed on the load-midspan curve at the moment when the first crack appears (Fig. 4). The experimental cracking moments of tested beams $\left(M_{c r c, e}\right)$ are presented in Table 3. The load-carrying capacities $\left(M_{u, e}\right)$ and failure modes of tested beams are also recorded and presented in Table 3 to evaluate the ratio between cracking moment and load-carrying capacity. The relationship between the cracking moments and 
the steel reinforcement ratios of the groups of beams with fixed GFRP reinforcement ratios are illustrated in Fig. 5. The relationship between the cracking moments and the GFRP reinforcement ratios of the groups of beams with fixed steel reinforcement ratios are also presented in Fig. 6.

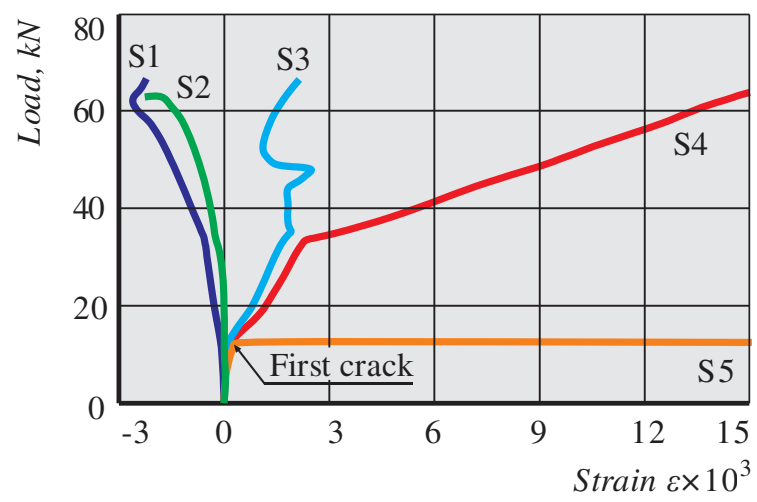

Fig. 3 Load versus strain curve of the concrete and reinforcements (beam B2.2G10-2S10)

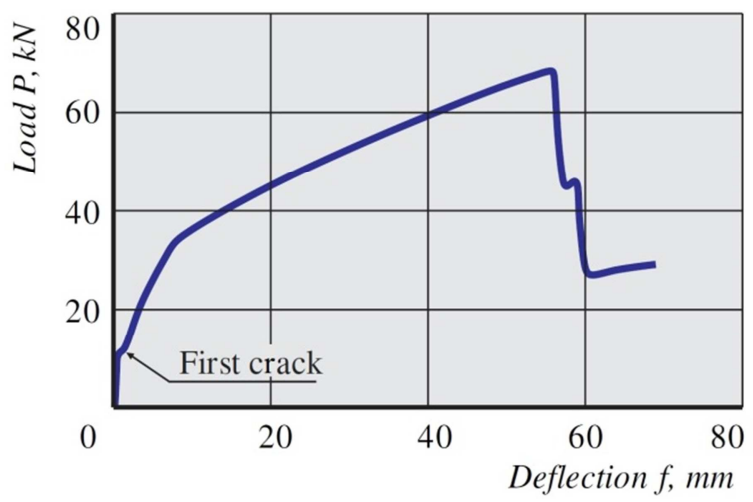

Fig. 4 Load versus midspan deflection curve (beam B2.2G10-2S10)

Table 3 The cracking moment of tested hybrid GFRP/steel RC beams

\begin{tabular}{|c|c|c|c|c|c|c|c|c|c|c|c|c|c|c|c|c|c|}
\hline \multirow{2}{*}{$\begin{array}{l}\text { Beam } \\
\text { ID }\end{array}$} & \multicolumn{12}{|c|}{ Experimental } & \multicolumn{5}{|c|}{ Theoretical } \\
\hline & $\begin{array}{r}\varepsilon_{s, e} \\
\times 10^{4} \\
\end{array}$ & $\begin{array}{r}\varepsilon_{f, e} \\
\times 10^{4} \\
\end{array}$ & $\begin{array}{r}\varepsilon_{b t, e} \\
\times 10^{4} \\
\end{array}$ & $\begin{array}{l}\sigma_{s, e}, \\
\mathrm{kN}\end{array}$ & $\begin{array}{l}\sigma_{f, e}, \\
\mathrm{kN}\end{array}$ & $\sigma_{s, e} / \sigma_{f, e}$ & $\begin{array}{c}\sigma_{s, e} / \sigma_{s y} \\
\%\end{array}$ & $\begin{array}{c}\sigma_{f, e} / f_{f u}, \\
\%\end{array}$ & $\begin{array}{c}M_{c r, e}, \\
\mathrm{kNm}\end{array}$ & $\begin{array}{l}M_{u, e}, \\
\mathrm{kNm}\end{array}$ & $\begin{array}{c}M_{c r c, e} \\
M_{u, e}\end{array}$ & \begin{tabular}{|c} 
Failure \\
mode
\end{tabular} & $\begin{array}{r}\varepsilon_{s, t} \\
\times 10^{4} \\
\end{array}$ & $\begin{array}{r}\varepsilon_{f, t} \\
\times 10^{4}\end{array}$ & $\begin{array}{r}\varepsilon_{b t, t} \\
\times 10^{4} \\
\end{array}$ & $\begin{array}{c}M_{c r c, t}, \\
\mathrm{kNm}\end{array}$ & $\begin{array}{l}M_{c r c, t} / \\
M_{c r c, e}\end{array}$ \\
\hline B1.2G10 & - & 1.65 & 1.72 & - & 7.3 & - & - & 0.73 & 5.35 & 24.1 & 0.22 & RG & - & 1.23 & 1.67 & 5.73 & 1.07 \\
\hline B2.2G10-2S10 & 0.86 & 1.29 & 1.73 & 17.2 & 5.7 & 3.02 & 4.17 & 0.57 & 6.20 & 34.4 & 0.18 & SY-RG & 0.82 & 1.12 & 1.70 & 6.60 & 1.06 \\
\hline B3.2G10-2S14 & 0.83 & 1.12 & 1.40 & 16.6 & 5.0 & 3.32 & 4.03 & 0.5 & 6.20 & 38.1 & 0.16 & SY-CC & 0.57 & 1.15 & 1.74 & 6.30 & 1.02 \\
\hline B4.2G14 & - & 1.31 & 1.47 & - & 5.8 & - & - & 0.58 & 6.20 & 41.4 & 0.15 & $\mathrm{CC}$ & - & 1.11 & 1.65 & 6.30 & 1.02 \\
\hline B5.2G14-2S10 & 1.00 & 1.14 & 1.76 & 20 & 5.1 & 3.92 & 4.85 & 0.51 & 6.40 & 48.4 & 0.13 & SY-CC & 0.83 & 1.10 & 1.72 & 6.47 & 1.01 \\
\hline B6.2G14-2S14 & 0.75 & 0.99 & 1.62 & 15 & 4.4 & 3.41 & 3.64 & 0.44 & 6.50 & 56.5 & 0.12 & SY-CC & 0.70 & 1.08 & 1.76 & 6.76 & 1.04 \\
\hline B7.3G14 & - & 1.30 & 1.64 & - & 5.8 & - & - & 0.58 & 6.65 & 52.4 & 0.13 & $\mathrm{CC}$ & - & 1.18 & 1.65 & 6.85 & 1.03 \\
\hline B8.3G14-2S10 & 0.73 & 1.03 & 1.51 & 14.6 & 4.6 & 3.17 & 3.54 & 0.46 & 6.40 & 50.0 & 0.13 & SY-CC & 0.75 & 1.08 & 1.72 & 6.94 & 1.08 \\
\hline B9.3G14-2S14 & 0.93 & 1.39 & 1.86 & 18.6 & 6.2 & 3.00 & 4.51 & 0.62 & 6.80 & 56.7 & 0.12 & SY-CC & 0.76 & 1.21 & 1.77 & 7.40 & 1.09 \\
\hline
\end{tabular}

*Note: RG refers to the rupture of GFRP, SY refers to steel yielding, and CC refers to concrete crushing.
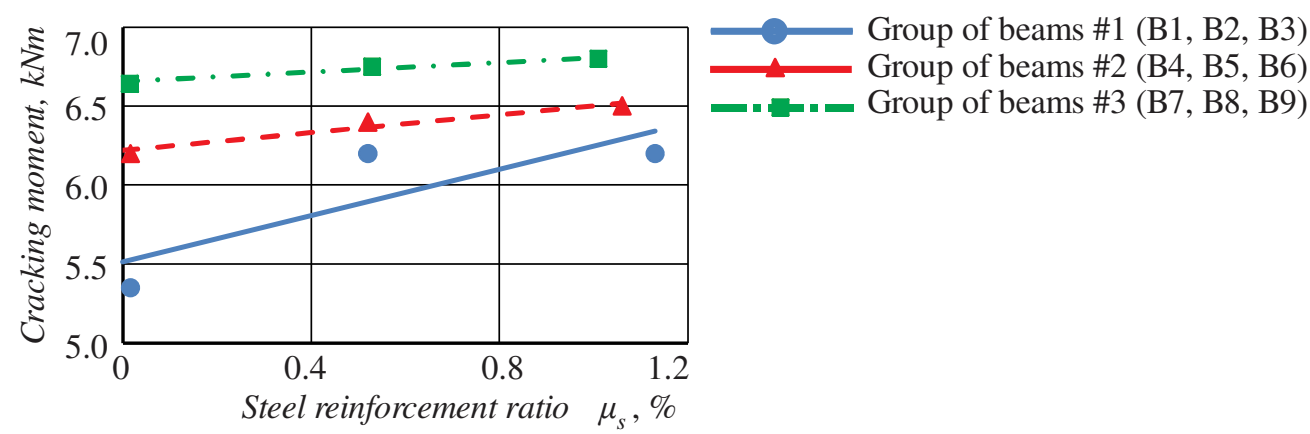

Fig. 5 Cracking moment versus steel reinforcement ratio curves of the groups of beams with fixed GFRP reinforcement ratios

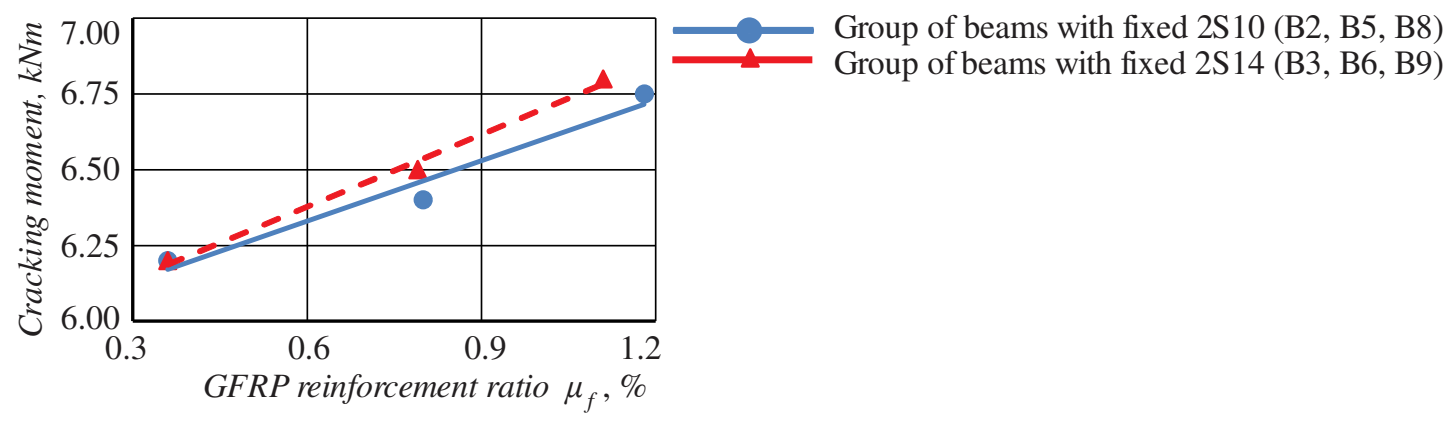

Fig. 6 Cracking moment versus GFRP reinforcement ratio curves of the groups of beams with fixed steel reinforcement ratios 
It is well known that the cracking moment depends on beam dimensions, properties of materials, and reinforcement ratios $[28,30]$. It can be seen in Figs. 5-6 that the reinforcements significantly affect the cracking moment of hybrid GFRP/steel RC beams. As GFRP or steel reinforcement ratios increase, the cracking moment of tested beams linearly increases. As can be seen in Fig. 5, in the groups of hybrid beams with fixed GFRP reinforcement ratio, the effect of steel reinforcement on cracking moment decreases with the increase of the GFRP reinforcement ratio. In the group of beams \#1 $\left(\mu_{f}=0.36 \%\right)$, when the steel reinforcement ratio increases from 0 to $1.13 \%$, the cracking moment of hybrid GFRP/steel beams increases to $15.9 \%$, while in the group of beams \#2 $\left(\mu_{f}=0.8 \%\right)$ and \#3 $\left(\mu_{f}=1.17 \%\right)$ the corresponding values are $4.8 \%$ and $2.3 \%$ respectively. When the steel reinforcement ratios are fixed, the cracking moment of hybrid GFRP/steel RC beams also increases with the increase of the GFRP reinforcement ratio. However, the effect of GFRP reinforcement on the cracking moment of the hybrid beam is less than that of steel rebars. In the groups of beams with fixed steel reinforcement (groups 2S10 and 2S14 in Fig. 6), the cracking moments of hybrid beams increase to $8.8 \%$ and $9.7 \%$ respectively. For the tested beams, the experimental cracking moment to load-carrying capacity ratio $\left(M_{c r c, e} / M_{u, e}\right)$ varies from 0.12 to 0.22 (Table 3 ), and this ratio decrease with the increase of the GFRP or steel reinforcement ratio.

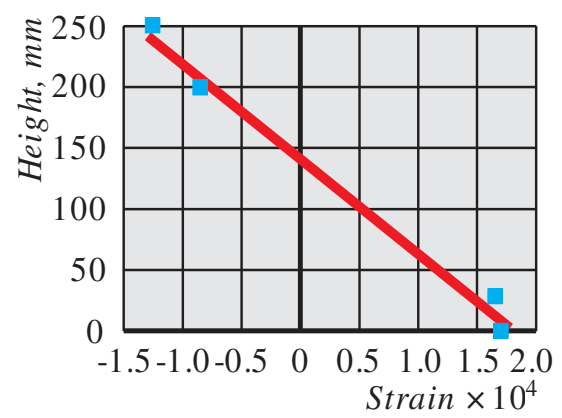

(a) Beams B1.2G10

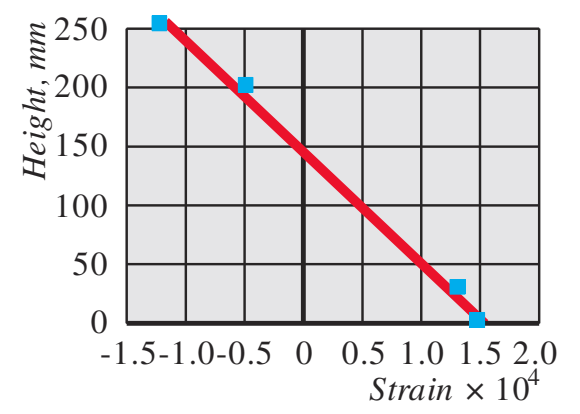

(d) Beams B4.2G14

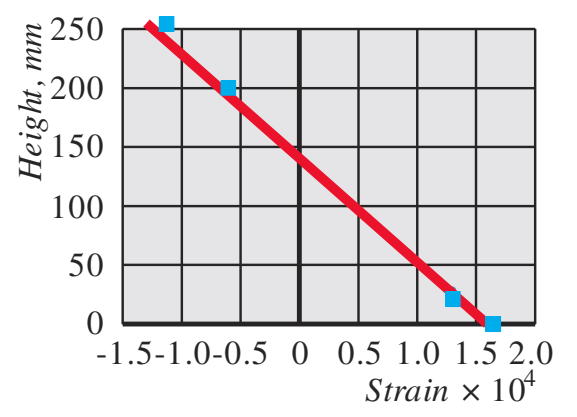

(g) Beams B7.3G14

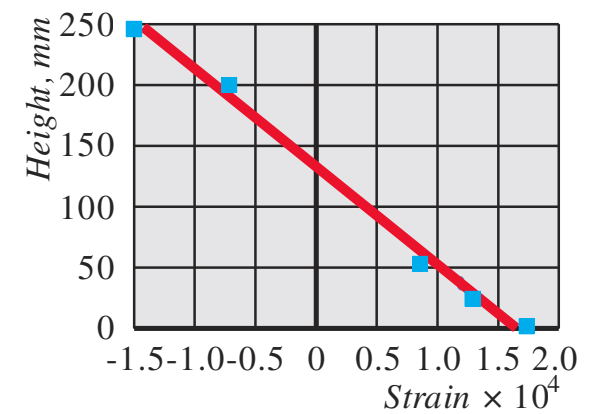

(b) Beams B2.2G10-2S10

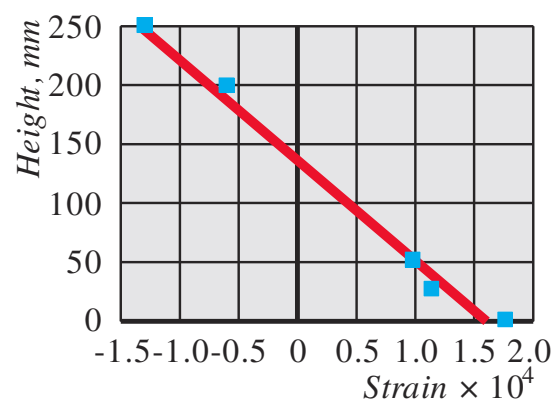

(e) Beams B5.2G14-2S10

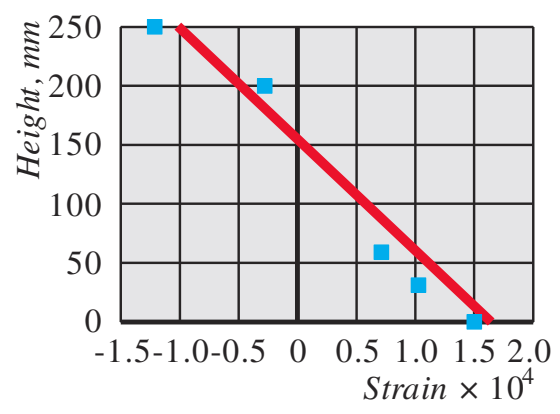

(h) Beams B8.3G14-2S10

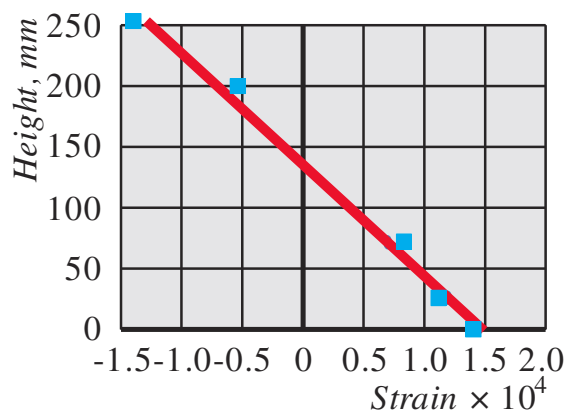

(c) Beams B3.2G10-2S14

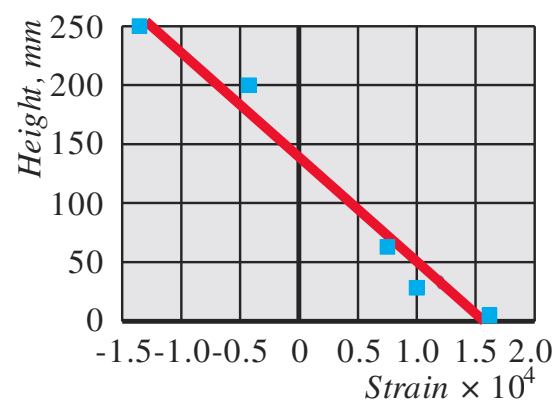

(f) Beams B6.2G14-2S14

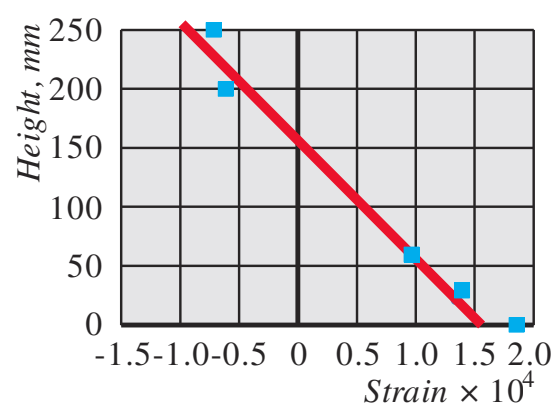

(i) Beams B9.3G14-2S14

Fig. 7 Distribution of strains on the cross-section at the fist cracking moment

Fig. 7 presents the distribution of strain on the cross-section of tested beams at the moment when the first crack appears. As can be seen, the plane cross-section assumption is satisfied for hybrid FRP/steel RC beams. To clarify the contribution of each type of longitudinal reinforcements to the cracking moment, the maximum experimental tensile strains and stresses of $\operatorname{GFRP}\left(\varepsilon_{f, e}\right.$ and $\left.\sigma_{f, e}\right)$ and steel rebars $\left(\varepsilon_{s, e}\right.$ and $\left.\sigma_{s, e}\right)$ before the appearance of the first crack are reported in Table 3 . The 
maximum tensile strain in concrete $\left(\varepsilon_{b t, e}\right)$ at this moment is also presented in Table 3 . Due to the elastic behavior of reinforcements in this stage, the values of the tensile stresses in GFRP and steel rebars are determined by multiplying the measured tensile strains by the corresponding Young's moduli (44.3 GPa and $200 \mathrm{GPa}$, Table 2).

As can be seen in Table 3, due to the high Young's modulus of steel rebars, at the first cracking moment, the stress in steel bars is about 3.02 to 3.92 times higher than that in GFRP rebars, and is about $3.00 \%$ to $4.85 \%$ of the yield strength. That fact has proven that both GFRP and steel reinforcement affects the cracking moment of hybrid GFRP/steel RC beams, but the contribution of GFRP reinforcement in this stage is negligible as compared to steel, and the stress in GFRP is about $0.44 \%$ to $0.73 \%$ of ultimate tensile strength. These results are consistent with the findings reported by most other researchers [27-28, 31] and are contrary to the results presented in [32]. In addition, experimental research results show that, as the first crack appears, the maximum tensile strain in the outermost concrete fiber $\left(\varepsilon_{b t, e}\right)$ reaches the value of $1.47 \times 10^{-4}$ to $1.86 \times 10^{-4}$, which meets the recommended ultimate tensile strain of concrete $\varepsilon_{b t u}=1.5 \times 10^{-4}$ in SP 63.13330:2018 [33]. In addition, the recorded maximum compressive strains in the outermost concrete fiber $\left(\varepsilon_{b, e}\right)$ before the appearance of the first crack vary from $0.91 \times 10^{-4}$ to $1.67 \times 10^{-4}$, which are much less than the ultimate compressive strain of concrete.

\section{An Analytical Method for Calculating the Cracking Moment of Hybrid FRP/Steel RC Beam}

As reported in the introduction and as indicated from the experimental results, the hybrid GFRP/steel reinforcement significantly affects the cracking moment. Therefore, using the recommendations of the existing design codes which neglect the contribution of reinforcements leads to the underestimation of the cracking moment. This section introduces an analytical method for calculating the cracking moment of FRP/steel RC beams based on the plane cross-section assumption and equations of equilibrium.

The bilinear stress-strain relationship of concrete introduced in SP 63.13330:2018 [33] is used in the calculation (Fig. 8). At the first cracking moment, the maximum strain in the outermost tensile concrete fiber reaches the ultimate value $\varepsilon_{b t 2}=$ $1.5 \times 10^{-5}$ according to the stress-strain relationship in Fig. 8. Before the concrete cracks, assuming that the concrete in compression behaves elastically, the stress distributes in triangular form. In the tension zone, the stress distributes in trapezoid form with the maximum stress equal to the tensile strength $R_{b t}$ according to the stress-strain relationship in Fig. 8. The distributions of strain and stress on the cross-section are presented in Fig. 9.

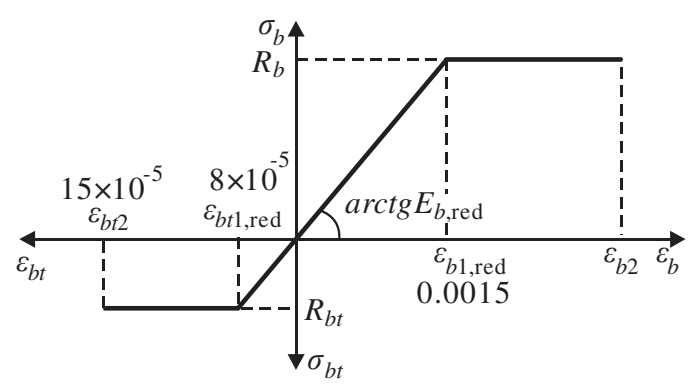

Fig. 8 Bilinear stress-strain relationship of concrete [33]

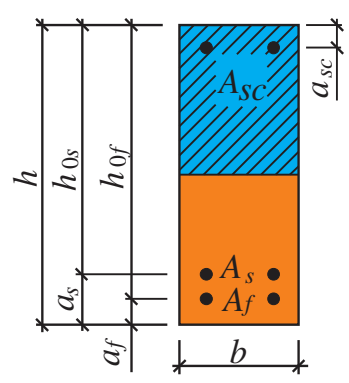

(a) Cross-section

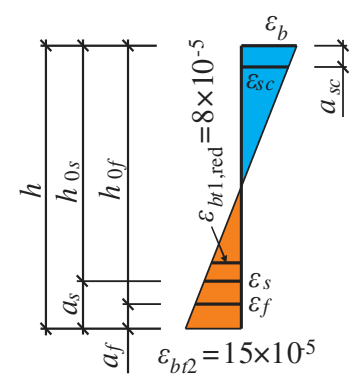

(b) Distribution of strains

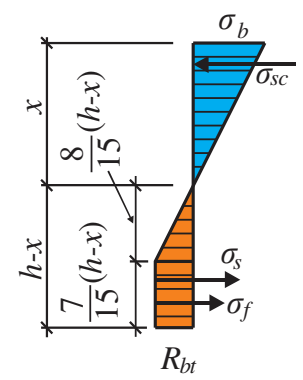

(c) Distribution of stress

Fig. 9 Stress and strain distributions for calculating the cracking moment 
The maximum strains in the outermost compressive concrete fiber $\varepsilon_{b}$, in the compressive steel rebars $\varepsilon_{s c}$, in the tensile steel rebars $\varepsilon_{s}$, and in the tensile GFRP rebars $\varepsilon_{f}$ are determined according to $\varepsilon_{b t 2}$ by using the plane cross-section assumption, i.e., according to the strain distribution shown in Fig. 9(b). The stress in concrete and reinforcements can be found by using the obtained strains in materials.

Before the first crack appears, the stress in the outermost compressive fiber of concrete $\sigma_{b}$ is determined by Eq. (1):

$$
\sigma_{b}=\varepsilon_{b} E_{b r e d}=\frac{\varepsilon_{b t 2} x}{h-x} \frac{R_{b}}{\varepsilon_{b 1, \text { red }}}=\frac{x}{h-x} \frac{R_{b}}{10}
$$

where $R_{b}$ is the prismatic strength of concrete; $x$ is the compression zone height; $\varepsilon_{b}$ is the maximum strain in the outermost compressive concrete fiber, which can be determined according to the Eq. (2) based on the plain cross section in Fig. 9(b); $E_{b r e d}$ is the reduced modulus of concrete, which is determined by Eq. (3) according to SP $63.13330: 2018$ [33].

$$
\begin{aligned}
& \varepsilon_{b}=\varepsilon_{b t 2} x /(h-x) \\
& E_{\text {bred }}=R_{b} / \varepsilon_{b 1, \text { red }}
\end{aligned}
$$

The stress in compressive reinforcement rebars is as follows:

$$
\sigma_{s c}=\varepsilon_{s c} E_{s}=\frac{\varepsilon_{b t 2}\left(x-a_{s c}\right) E_{s}}{h-x}
$$

where $E_{s}$ is the modulus of elasticity of steel; $\varepsilon_{s c}$ is the strain in compressive steel rebars and is calculated according to Fig. 9(b) by the following equation.

$$
\varepsilon_{s c}=\varepsilon_{b t 2}\left(x-a_{s c}\right) /(h-x)
$$

The stress in tensile steel rebars is as follows:

$$
\sigma_{s}=\varepsilon_{s} E_{s}=\frac{\varepsilon_{b t 2}\left(h-x-a_{s}\right) E_{s}}{h-x}
$$

where $\varepsilon_{s}$ is the strain in tensile steel reinforcement obtained from Fig. 9(b) as follows:

$$
\varepsilon_{s}=\varepsilon_{b t 2}\left(h-x-a_{s}\right) /(h-x)
$$

The stress in tensile FRP rebars is as follows:

$$
\sigma_{f}=\varepsilon_{f} E_{f}=\frac{\varepsilon_{b t 2}\left(h-x-a_{f}\right) E_{f}}{h-x}
$$

where $\varepsilon_{f}$ is the strain in GFRP rebars and determined according to Fig. 9(b) as follows:

$$
\varepsilon_{f}=\varepsilon_{b t 2}\left(h-x-a_{f}\right) /(h-x)
$$

The resultant forces of the compression zone of concrete $\left(N_{b}\right)$, of the compressive reinforcement $\left(N_{s c}\right)$, of the tensile steel $\left(N_{s}\right)$ and GFRP $\left(N_{f}\right)$ rebars, and in the tension zone of concrete $\left(N_{b t}\right)$ are calculated using the following equations: 


$$
\begin{aligned}
& N_{b}=\frac{\sigma_{b} b x}{2}=\frac{x^{2}}{h-x} \frac{b R_{b}}{20} \\
& N_{s c}=\sigma_{s c} A_{s c}=\frac{\varepsilon_{b t 2} E_{s}\left(x-a_{s c}\right) A_{s c}}{h-x} \\
& N_{s}=\sigma_{s} A_{s}=\frac{\varepsilon_{b t 2} E_{s}\left(h-x-a_{s}\right) A_{s}}{h-x} \\
& N_{f}=\sigma_{f} A_{f}=\frac{\varepsilon_{b t 2}\left(h-x-a_{f}\right) E_{f} A_{f}}{h-x} \\
& N_{b t}=N_{b t 1}+N_{b t 2}=\frac{7(h-x) R_{b t} b}{15}+\frac{4(h-x) R_{b t} b}{15}
\end{aligned}
$$

The equation of horizontal force equilibrium is as follows:

$$
\frac{x^{2}}{h-x} \frac{b R_{b}}{20}+\frac{\varepsilon_{b t 2} E_{s}\left(x-a_{s c}\right) A_{s c}}{h-x}=\frac{\varepsilon_{b t 2}\left(h-x-a_{s}\right) E_{s} A_{s}}{h-x}+\frac{\varepsilon_{b t 2}\left(h-x-a_{f}\right) E_{f} A_{f}}{h-x}+\frac{11(h-x) R_{b t} b}{15}
$$

By expanding Eq. (15) and setting the constants $A$ (16), $B$ (17), and $C$ (18), Eq. (15) is re-written as Eq. (19):

$$
\begin{aligned}
& A=\frac{R_{b} b}{20}-\frac{11 R_{b t} b}{15} \\
& B=\varepsilon_{b t 2}\left(E_{s} A_{s}+E_{s} A_{s c}+E_{f} A_{f}\right)+\frac{22 R_{b t} b h}{15} \\
& C=\varepsilon_{b t 2}\left(E_{s} A_{s} a_{s}-E_{s} A_{s c} a_{s c}+E_{f} A_{f} a_{f}-E_{s} A_{s} h-E_{f} A_{f} h\right)-\frac{11 R_{b t} b h^{2}}{15} \\
& A x^{2}+B x+C=0
\end{aligned}
$$

By solving Eq. (19) and choosing the compatible root meeting the condition $0<x<h$, the equations for calculating the compression zone height is expressed as follows:

$$
x=\frac{\sqrt{B^{2}-4 A C}-B}{2 A}
$$

By using the compression zone height $x$ (Eq. (20)) and defining the resultant forces in materials $\left(N_{b}, N_{s c}, N_{s}, N_{f}\right.$, and $\left.N_{b t}\right)$ according to Eq. (10) to Eq. (14), the first cracking moment $M_{c r c}$ can be determined by taking the moment about the axis passing through the neutral axis (Eq. (21)). The comparison results between the experimental cracking moments and the theoretical values $\left(M_{c r c, t}\right)$ of the tested beams obtained by Eq. (21) in Table 3 show good agreement. The deviation between the experimental and theoretical cracking moment is less than $9 \%$. In addition, the theoretical strains in the outermost compressive concrete fiber, in the steel tensile reinforcement, and in the tensile GFRP reinforcement obtained by Eq. (2), Eq. (7), and Eq. (9) respectively are also in good agreement with the experimental values (Table 3).

$$
M_{c r c}=\frac{2 x N_{b}}{3}+N_{s c}\left(x-a_{s c}\right)+N_{s}\left(h-x-a_{s}\right)+N_{f}\left(h-x-a_{f}\right)+\frac{23 N_{b t 1}(h-x)}{30}+\frac{16 N_{b t 2}(h-x)}{45}
$$


To verify the applicability of the proposed theory for determining the cracking moment of concrete beams reinforced with a combination of steel bars and different types of FRP bars, the experimental data of 24 tested hybrid FRP/steel RC beams in the literature are collected and compared as shown in Table 4. The comparison results prove the accuracy in estimating the cracking moment of concrete beams reinforced with hybrid FRP/steel rebars. The average value is 1.006 , the standard deviation is 0.076 , and the mean value is 0.995 .

Table 4 The comparison between experimental and theoretical cracking moments of concrete beams reinforced with a combination of different types of FRP and steel bars

\begin{tabular}{|c|c|c|c|c|c|c|c|c|c|c|c|c|c|c|c|c|}
\hline Ref. & Beam ID & $\begin{array}{c}b, \\
\mathrm{~mm}\end{array}$ & $\begin{array}{c}h, \\
\mathrm{~mm}\end{array}$ & $\begin{array}{c}a_{f}, \\
\mathrm{~mm}\end{array}$ & $\begin{array}{c}a_{s}, \\
\mathrm{~mm}\end{array}$ & $\begin{array}{c}A_{f}, \\
\mathrm{~mm}^{2}\end{array}$ & $\begin{array}{c}A_{s}, \\
\mathrm{~mm}^{2}\end{array}$ & $\begin{array}{l}A_{s c}, \\
\mathrm{~mm}^{2}\end{array}$ & $\begin{array}{l}a_{s c}, \\
\mathrm{~mm}\end{array}$ & $\begin{array}{c}E_{s}, \\
\mathrm{GPa}\end{array}$ & $\begin{array}{c}\text { Type of } \\
\text { FRP }\end{array}$ & $\begin{array}{c}E_{f}, \\
\mathrm{GPa}\end{array}$ & $\begin{array}{l}R_{m}, \\
\mathrm{MPa}\end{array}$ & $\begin{array}{c}M_{c r c, e}, \\
\mathrm{kNm}\end{array}$ & $\begin{array}{c}M_{c r c, t}, \\
\mathrm{kNm}\end{array}$ & $\begin{array}{l}M_{c r c, t} / \\
M_{c r c, e}\end{array}$ \\
\hline \multirow{4}{*}{ [25] } & B10/8S & 100 & 200 & 22 & 64 & 100.6 & 157 & 0 & 0 & 200 & GFRP & 39 & 30 & 2.5 & 2.39 & 0.96 \\
\hline & B10/6 & 100 & 200 & 21 & 64 & 56.6 & 157 & 0 & 0 & 200 & GFRP & 41 & 30 & 2.5 & 2.37 & 0.95 \\
\hline & B12/8 & 100 & 200 & 22 & 65 & 100.6 & 226 & 0 & 0 & 200 & GFRP & 39 & 30 & 2.7 & 2.42 & 0.90 \\
\hline & B12/6S & 100 & 200 & 21 & 65 & 56.6 & 226 & 0 & 0 & 200 & GFRP & 41 & 30 & 2.3 & 2.4 & 1.04 \\
\hline \multirow{4}{*}{ [23] } & GFRP-40S & 150 & 250 & 42 & 98 & 253.4 & 142.6 & 142.6 & 210 & 200 & GFRP & 48 & 32.7 & 5.4 & 5.4 & 1.00 \\
\hline & CFRP-40S & 150 & 250 & 40 & 95 & 142.6 & 142.6 & 142.6 & 210 & 200 & CFRP & 103 & 32.7 & 5.7 & 5.4 & 0.95 \\
\hline & GFRP-60S & 150 & 250 & 42 & 98 & 253.4 & 142.6 & 142.6 & 210 & 200 & GFRP & 48 & 49.3 & 7.43 & 7.11 & 0.96 \\
\hline & CFRP-60S & 150 & 250 & 40 & 95 & 142.6 & 142.6 & 142.6 & 210 & 200 & CFRP & 103 & 49.3 & 6.3 & 7.11 & 1.13 \\
\hline \multirow{16}{*}{ [26] } & B2S3 & 200 & 300 & 30 & 30 & 118.3 & 339.3 & 1.57 & 270 & 200 & BFRP & 43 & 25 & 13.2 & 11.85 & 0.90 \\
\hline & B3S2 & 200 & 300 & 30 & 30 & 177.5 & 226.2 & 1.57 & 270 & 200 & BFRP & 43 & 25 & 11.6 & 11.5 & 0.99 \\
\hline & B4S1 & 200 & 300 & 30 & 30 & 236.7 & 113.1 & 1.57 & 270 & 200 & BFRP & 43 & 25 & 10.4 & 11.1 & 1.07 \\
\hline & G2S3 & 200 & 300 & 30 & 30 & 259.8 & 339.3 & 1.57 & 270 & 200 & GFRP & 35 & 25 & 11.5 & 11.9 & 1.03 \\
\hline & G3S2 & 200 & 300 & 30 & 30 & 389.7 & 226.2 & 1.57 & 270 & 200 & GFRP & 35 & 25 & 10.1 & 11.6 & 1.15 \\
\hline & G4S1 & 200 & 300 & 30 & 30 & 519.6 & 113.1 & 1.57 & 270 & 200 & GFRP & 35 & 25 & 10.5 & 11.2 & 1.07 \\
\hline & G1S5 & 200.8 & 301.9 & 30 & 30 & 117.5 & 565.5 & 0 & 0 & 200 & GFRP & 46 & 24.4 & 13.3 & 12.7 & 0.95 \\
\hline & G2S4 & 199.8 & 301.1 & 30 & 30 & 234.9 & 452.4 & 0 & 0 & 200 & GFRP & 46 & 24.4 & 12.7 & 12.3 & 0.97 \\
\hline & G3S3 & 200.6 & 304.4 & 30 & 30 & 352.4 & 339.3 & 0 & 0 & 200 & GFRP & 46 & 24.4 & 10.9 & 12.2 & 1.12 \\
\hline & G4S2 & 198.6 & 304.6 & 30 & 30 & 469.9 & 226.2 & 0 & 0 & 200 & GFRP & 46 & 24.4 & 11 & 11.8 & 1.07 \\
\hline & B1S2 & 199.8 & 308 & 30 & 30 & 59.2 & 226.2 & 0 & 0 & 200 & BFRP & 43 & 24.4 & 11.8 & 11.7 & 0.99 \\
\hline & B1S4 & 200 & 300 & 30 & 30 & 59.2 & 452.4 & 1.57 & 270 & 200 & BFRP & 43 & 25 & 14 & 12.2 & 0.87 \\
\hline & G1S4 & 200 & 300 & 30 & 30 & 129.9 & 452.4 & 1.57 & 270 & 200 & GFRP & 35 & 25 & 13.2 & 12.3 & 0.93 \\
\hline & B2S1 & 199.2 & 301.7 & 30 & 30 & 118.3 & 113.1 & 0 & 0 & 200 & BFRP & 43 & 24.4 & 10.8 & 10.9 & 1.01 \\
\hline & G1S2 & 198.6 & 304.9 & 30 & 30 & 117.5 & 226.2 & 0 & 0 & 200 & GFRP & 46 & 24.4 & 11.4 & 11.5 & 1.01 \\
\hline & G2S1 & 202 & 301.6 & 30 & 30 & 234.9 & 113.1 & 0 & 0 & 200 & GFRP & 46 & 24.4 & 9.9 & 11.1 & 1.12 \\
\hline \multicolumn{16}{|c|}{$\begin{array}{r}\text { Average } \\
\text { Standard deviation } \\
\text { Mean }\end{array}$} & $\begin{array}{l}1.006 \\
0.076 \\
0.995 \\
\end{array}$ \\
\hline
\end{tabular}

\section{Parametric Study}

As mentioned above, besides the section geometry and mechanical properties of concrete, the longitudinal reinforcements also significantly affect the cracking moment of hybrid FRP/steel RC beams. In this section, a parametric study of the effects of the longitudinal FRP and steel reinforcement ratios and Young's modulus of FRP rebars on the cracking moment of hybrid FRP/steel RC beams is carried out using the proposed formula (Eq. (21)).

First, the influence of hybrid FRP/steel reinforcement ratios on the cracking moment are performed with the following input data: $b \times h=300 \times 600 \mathrm{~mm} ; R_{b}=30 \mathrm{MPa} ; R_{b t}=2.5 \mathrm{MPa} ; E_{b}=32 \mathrm{GPa} ; E_{s}=200 \mathrm{GPa} ; \sigma_{s y}=400 \mathrm{MPa} ; E_{f}=50 \mathrm{GPa} ; R_{f}=$ $1000 \mathrm{MPa}$. The distances from the centroid of the steel rebars and FRP rebars to the outermost tensile concrete fiber are chosen equally: $a_{f}=a_{s}=40 \mathrm{~mm}$. By considering the recommendations in [20], the steel and FRP reinforcement ratios are selected to vary from $0 \%$ to a maximum $4 \%$ (i.e, the area of each type of reinforcements varies from $0 \mathrm{~cm}^{2}$ to $67.2 \mathrm{~cm}^{2}$ ). By conducting nonlinear regression analysis, the relationship between cracking moment calculated by Eq. (21) and hybrid steel/FRP reinforcement ratios is expressed by Eq. (22). It should be noticed that, the adjusted coefficient of multiple determination $\left(R^{2}\right)$ of regression model in Eq. (21) is higher than 0.9999. 


$$
M_{c r c}=M_{c r c, b}+3.597 \mu_{f}+15.077 \mu_{s}+5.49 \mu_{f}^{2}-0.1567 \mu_{s}^{2}
$$

where $M_{c r c, b}$ is the cracking moment of plain concrete beam; $\mu_{f}$ and $\mu_{s}$ are in percent (\%).

The response surface which expresses the relationship among cracking moment, FRP, and steel reinforcement ratios according to Eq. (22) is shown in Fig. 10. The results of the parametric study on the current section and properties of beam show that the cracking moment increases to $93.7 \%$ when the steel reinforcement ratios increase from $0 \%$ to $4 \%$. Meanwhile, the corresponding value for the case of the increasing FRP reinforcement is only $24.3 \%$. This outcome affirms the above conclusion of the lower contribution of FRP reinforcement on the cracking moment of hybrid FRP/steel RC beam in comparison with the steel reinforcement. In addition, as reported in previous studies, the ratio $A_{f} / A_{s}$ significantly affects the flexural behavior of FRP/steel RC beams. As found from the parametric study, this ratio also significantly affects the cracking moment of FRP/steel RC beams. Namely, with a constant total area of hybrid FRP/steel reinforcement, the cracking moment decreases with an increase in the $A_{f} / A_{s}$ ratio.

The effect of Young's modulus of FRP on the cracking moment is also investigated on the above-mentioned cross section and properties of materials. The cross section is reinforced with three groups of steel and FRP reinforcement: the first group $A_{s}=4 \mathrm{~cm}^{2}$ and $A_{f}=4 \mathrm{~cm}^{2}$ (minimum hybrid FRP/steel reinforcement ratio [20]), the second group $-A_{s}=25 \mathrm{~cm}^{2}$ and $A_{f}=25$ $\mathrm{cm}^{2}$ (compatible hybrid FRP/steel reinforcement ratio [20]), and the third group $-A_{s}=50 \mathrm{~cm}^{2}$ and $A_{f}=50 \mathrm{~cm}^{2}$ (maximum hybrid FRP/steel reinforcement ratio [20]). The modulus of elasticity of FRP reinforcement varies from $50 \mathrm{GPa}$ to $200 \mathrm{GPa}$. It can be seen in Fig. 11 that the cracking moment of hybrid FRP/steel RC beams is linearly proportional to Young's modulus of FRP reinforcement. Besides, the effect of Young's modulus of FRP reinforcement on cracking moment increases with the increase of the FRP reinforcement ratio.

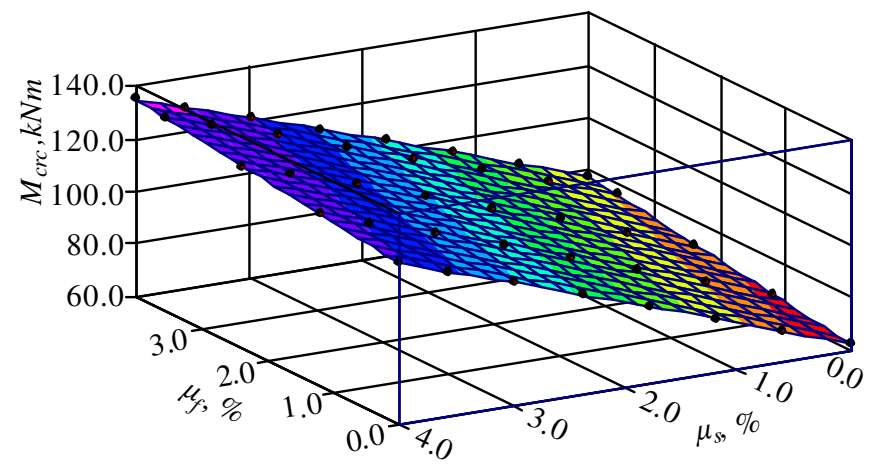

Fig. 10 The response surface among cracking moment, FRP, and steel reinforcement ratios

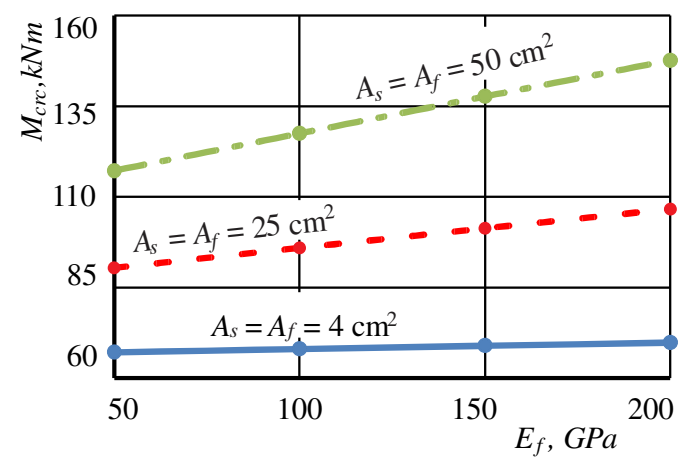

Fig. 11 The relationship between Young's modulus of FRP reinforcement and cracking moment

\section{Conclusions}

In this study, the cracking moment of hybrid FRP/steel RC beams was experimentally and theoretically investigated. Based on the study results, the following conclusions may be drawn: 
(1) The cracking moment of hybrid FRP/steel RC beams is linearly proportional with the steel and FRP reinforcement ratios.

(2) In the scope of the experimental study, the cracking moment to load-carrying capacity ratio of hybrid GFRP/steel RC beams varies from $12 \%$ to $22 \%$, and this ratio reduces with increasing total hybrid reinforcement ratio.

(3) Both steel and FRP rebars affect the cracking moment of hybrid FRP/steel RC beams. However, due to higher modulus of elasticity of steel in comparison with the FRP reinforcement, the contribution of steel rebars on the cracking moment of hybrid FRP/steel RC beams are more significant in comparison with FRP reinforcement.

(4) The proposed analytical method, which is based on the nonlinear stress-strain relationship of concrete and considered the contribution of hybrid reinforcements, accurately estimates the cracking moment of hybrid FRP/steel RC beams.

(5) The modulus of elasticity of FRP reinforcement also affects the cracking moment of FRP/steel RC beams, the cracking moment increases with the increase of Young's modulus of FRP reinforcement.

It should be stressed that the above conclusions are based on the study results of concrete beams made from normal strength concrete reinforced with optimal hybrid FRP/steel reinforcement ratio. The applicability of these conclusions to other types of concrete and very high hybrid reinforcement ratios is unknown. Further studies are necessary.

\section{Conflicts of Interest}

The authors declare no conflict of interest.

\section{References}

[1] S. A. Jabbar and S. B. H. Farid, "Replacement of Steel Rebars by GFRP Rebars in the Concrete Structures," Karbala International Journal of Modern Science, vol. 4, no. 2, pp. 216-227, June 2018.

[2] C. Jeetendra, K. Suresh, and A. Hussain, "Application of FRP in Concrete Structures," International Journal of Engineering Associates, vol. 4, no. 8, pp. 50-51, August 2015.

[3] C. Barris, L. Torres, J. Comas, and C. Miàs, "Cracking and Deflections in GFRP RC Beams: An Experimental Study," Composites Part B: Engineering, vol. 55, pp. 580-590, December 2013.

[4] W. Qu, X. Zhang, and H. Huang, "Flexural Behavior of Concrete Beams Reinforced with Hybrid (GFRP and Steel) Bars," Journal of Composites for Construction, vol. 13, no. 5, pp. 350-359, Octorber 2009.

[5] D. Lau and H. Pam, "Experimental Study of Hybrid FRP Reinforced Concrete Beams," Engineering Structures, vol. 32 , no. 12, pp. 3857-3865, December 2010.

[6] J. Zhang, W. Ge, H. Dai, and Y. Tu, "Study on the Flexural Capacity of Concrete Beam Hybrid Reinforced with FRP Bars and Steel Bars," 5th International Conference on FRP Composites in Civil Engineering, September 2010, pp. 304-307.

[7] S. H. Alsayed and A. M. Alhozaimy, "Ductility of Concrete Beams Reinforced with FRP Bars and Steel Fibers," Journal of Composite Materials, vol. 33, no. 19, pp. 1792-1806, October 1999.

[8] M. A. Aiello and L. Ombres, "Structural Performances of Concrete Beams with Hybrid (Fiber-Reinforced Polymer-Steel) Reinforcements," Journal of Composites for Construction, vol. 6, no. 2, pp. 133-140, January 2002.

[9] K. H. Tan, "Behavior of Hybrid FRP-Steel Reinforced Concrete Beams," 3rd International Symposium on Non-Metallic (FRP) Reinforcement for Concrete Structures, October 1997, pp. 487-493.

[10] P. D. Nguyen, V. H. Dang, and N. A. Vu, "Performance of Concrete Beams Reinforced with Various Ratios of Hybrid GFRP/Steel Bars," Civil Engineering Journal, vol. 6, no. 9, pp. 1652-1669, September 2020.

[11] I. Kara, A. Ashour, and M. Köroğlu, "Flexural Behavior of Hybrid FRP/Steel Reinforced Concrete Beams," Composite Structures, vol. 129, pp. 111-121, October 2015.

[12] L. Pang, W. Qu, P. Zhu, and J. Xu, "Design Propositions for Hybrid FRP-Steel Reinforced Concrete Beams," Journal of Composites for Construction, vol. 20, no. 4, 04015086, August 2016.

[13] X. Gu, Y. Dai, and J. Jiang, "Flexural Behavior Investigation of Steel-GFRP Hybrid-Reinforced Concrete Beams Based on Experimental and Numerical Methods," Engineering Structures, vol. 206, 110117, March 2020.

[14] B. Jia, S. Liu, X. Liu, and R. Wang, "Flexural Capacity Calculation of Hybrid Bar Reinforced Concrete Beams," Materials Research Innovations, vol. 18, no. Supp 2, pp. S2-836-S2-840, May 2014. 
[15] J. Zhang, W. Ge, H. Dai, and Y. Tu, "Study on the Flexural Capacity of Concrete Beam Hybrid Reinforced with FRP Bars and Steel Bars," 5th International Conference on FRP Composites in Civil Engineering, September 2010, pp. $304-307$.

[16] Y. Yang, Z. Y. Sun, G. Wu, D. F. Cao, and Z. Q. Zhang, "Flexural Capacity and Design of Hybrid FRP-Steel-Reinforced Concrete Beams," Advances in Structural Engineering, vol. 23, no. 7, pp. 1290-1304, May 2020.

[17] N. Duy Phan and D. Viet Quoc, "Limiting Reinforcement Ratios for Hybrid GFRP/Steel Reinforced Concrete Beams," International Journal of Engineering and Technology Innovation, vol. 11, no. 1, pp. 1-11, January 2021.

[18] F. Maleki and A. Kheyroddin, "Investigation of Cracking Moment in RC Beams with GFRP Bars," vol. 2, pp. 37-47, January 2017.

[19] X. Ruan, C. Lu, K. Xu, G. Xuan, and M. Ni, "Flexural Behavior and Serviceability of Concrete Beams Hybrid-Reinforced with GFRP Bars and Steel Bars," Composite Structures, vol. 235, 111772, March 2020.

[20] G. Xingyu, D. Yiqing, and J. Jiwang, "Flexural Behavior Investigation of Steel-GFRP Hybrid-Reinforced Concrete Beams Based on Experimental and Numerical Methods," Engineering Structures, vol. 206, pp. 110-117, March 2020.

[21] W. Ge, J. Zhang, D. Cao, and Y. Tu, "Flexural Behaviors of Hybrid Concrete Beams Reinforced with BFRP Bars and Steel Bars," Construction and Building Materials, vol. 87, pp. 28-37, July 2015.

[22] H. Alkhudery, O. Albuthbahak, and H. Alkatib, "Investigation of Effective Hybrid FRP and Steel Reinforcement Ratio for Concrete Members," Journal of Engineering and Applied Sciences, vol. 13, no. 13, pp. 5150-5161, September 2018.

[23] S. Kim and S. Kim, "Flexural Behavior of Concrete Beams with Steel Bar and FRP Reinforcement," Journal of Asian Architecture and Building Engineering, vol. 18, no. 2, pp. 89-97, May 2019.

[24] W. Ge, Y. Wang, A. Ashour, W. Lu, and D. Cao, "Flexural Performance of Concrete Beams Reinforced with Steel-FRP Composite Bars," Archives of Civil and Mechanical Engineering, vol. 20, pp. 1-17, June 2020.

[25] A. S. Mohamed, "Flexural Behavior and Design of Steel-GFRP Reinforced Concrete Beams," ACI Materials Journal, vol. 110, no. 6, pp. 677-686, November 2013.

[26] S. Kartal and I. Kalkan, "First Cracking Moments of Hybrid Fiber Reinforced Polymer-Steel Reinforced Concrete Beams," International Journal of Civil and Environmental Engineering, vol. 13, no. 9, pp. 527-533, 2019.

[27] J. Valivonis and T. Skuturna, "Cracking and Strength of Reinforced Concrete Structures in Flexure Strengthened with Carbon Fibre Laminates," Journal of Civil Engineering and Management, vol. 13, pp. 317-323, December 2007.

[28] D. Gao, P. You, and Z. Changhui, "Crack Resistant Performance and Crack Width of One-Way Slabs Strengthened with FRP,” Applied Mechanics and Materials, vols. 71-78, pp. 3810-3815, July 2011.

[29] ACI committee 440, "Guide for the Design and Construction of Structural Concrete Reinforced with Fiber-Reinforced Polymer (FRP) Bars,"American Concrete Institute, ACI440.1R-15, March 2015.

[30] J. C. McCormac and R. H. Brown, Design of Reinforced Concrete, 10th ed. United States: Wiley, 2015.

[31] W. J. Ge, A. F. Ashour, J. Yu, P. Gao, D. F. Cao, C. Cai, et al., "Flexural Behavior of ECC-Concrete Hybrid Composite Beams Reinforced with FRP and Steel Bars,” Journal of Composites for Construction, vol. 23, no. 1, 04018069, February 2019.

[32] S. F. Liu, M. Y. Hou, X. Liu, and R. H. Wang, "Analysis of Cracking Moment and Immediate Deflection in FRP Rebars Reinforced Concrete Beams,” Advanced Materials Research, vols. 671-674, pp. 618-621, March 2013.

[33] Concrete and Reinforced Concrete Structures, Russian Technical Standard SP 63.13330, 2019.

Copyright $\subset$ by the authors. Licensee TAETI, Taiwan. This article is an open access article distributed under the terms and conditions of the Creative Commons Attribution (CC BY-NC) license (https://creativecommons.org/licenses/by-nc/4.0/). 